\title{
Digital Technologies and Music Digitisation: Challenges and Opportunities for the Nepalese Music Industry
}

Research Article

\author{
Subash Giri* \\ Department of Music, University of Alberta, Edmonton, Alberta, Canada
}

Received August 26, 2019; Accepted May 3, 2021

\begin{abstract}
This paper investigates the current legitimate digital music business trends and models created by the innovation of new digital technologies and examines their pertinence in the Nepalese music industry. Further, it scrutinises neighbouring music markets and juxtaposes the Nepalese music market against their current market trends. Based on eight in-depth semi-structured interviews with executives and stakeholders of different major, medium and independent Nepalese record labels, the paper examines two questions: what is preventing Nepalese recorded music from being found digitally and accessible legally; and what are the opportunities, gaps and requirements that confront the search for a commercially viable route for the optimal digital music business model to make Nepalese music digitally and legally accessible, both locally and globally?

Keywords: Music digitisation • music business • digital technology • Nepalese music industry • digital distribution models
\end{abstract}

\section{Introduction}

"[The] [m]usic industry during less than a decade has completely shifted its centre of gravity from the physical to the virtual from the Disk to the Cloud. ${ }^{1}$ Music is no longer something the mainstream audience owns and collects - Music is in the Cloud" (Wikström 2009: 4).

In the past decade and a half, digital technology has significantly transformed the entire music industry. The digital revolution has played a crucial role in the means and medium of music distribution. New digital technology has facilitated new digital business models and has received much attention in the last few years. Statistics show that music industry digital revenues account for more than half $(58.9 \%)$ of the global recorded music market with a $34.0 \%$ increase in streaming revenues, whereas physical revenues account for just around a quarter of the overall market with a decline of 10.1\% in 2018 (IFPI 2019a, 2019b). Music marketing has undergone tremendous changes, and advanced technology has created various opportunities for music marketers to distribute and sell their products (Ogden, Ogden, \& Long 2011).

A wide range of models and licensed music services are being developed, offering customers instant access to music. The music industry is always finding better and improved ways to enhance its business by using technology. However, in the case of the Nepalese music industry, it still employs the traditional business model and distributing channels for selling music. The traditional business model distributes music using CDs, cassette tapes and other

1 'The Cloud' has been used as a metaphor to denote the internet.

*E-mail: sgiri@ualberta.ca, girisubashchandra@gmail.com, Website: https://subashgiri.com/ 
physical recordings. On the other hand, the digital business model distributes music through digital forms such as downloading or streaming, forgoing physical mediums. Despite the dramatic shift of global music into digitisation, the Nepalese music industry seems unaware of this phenomenon, and there remains a distinct gap between the global trend and the Nepalese market. The technological lag in the Nepalese music industry may have a profound impact on its current and future revenue streams, as well as a loss of potential consumers who are expecting instant access to music content rather than a physical visit to music stores.

This paper explores the Nepalese music industry's current circumstances: the impacts of digital technology in the Nepalese music industry; the barriers preventing both a Nepalese and global audience from finding Nepalese recorded music digitally and legally; and the opportunities, gaps and requirements needed for an optimal digital music business model to have a commercially viable route. Further, it attempts to understand the current trend and models of the global music industry created by the innovation of new digital technologies. The findings and discussion in this paper are based on the information from eight in-depth semi-structured interviews taken from February 2016 to August 2019 with executives and stakeholders of different major, medium and independent Nepalese record labels, who have a rich knowledge of and experience in the Nepalese music industry and have been running music businesses for more than two decades. All the interviews were conducted and initially transcribed into Nepalese. Later, they were translated into English for analysis and discussion. In addition, the paper makes a thorough analysis of Nepal's two neighbouring music markets and discusses two relevant theories focusing on technology, digital music business, economy and development: the theory of technology by W. Brian Arthur, and the theory of economic development by Joseph A. Schumpeter. The research also uses secondary data from literature sources, government sources, media sources and local and international music industry reports. The paper begins by considering current scholarly work on digital technology and music digitisation, followed by an overview of recent discourses and theorisation on technology's connection to the digital music business.

\section{Issues and Discourses on Digital Technologies and Music Digitisation}

Many theories, business models and strategies have been proposed by different scholars to define music digitisation and digital technology. A wide range of terminologies and discourses are occurring in academia to address the issues and impacts of digital technologies and music digitisation. Patrik Wikström provides an example of the rock artist Trent Reznor and his project Ghost I-IV to show how digital technology is employed to create a new business model (Wikström 2009: 1-2). He applies the term 'cloud' to indicate the transformation of music industry from a physical to virtual ${ }^{2}$ structure as an outcome of digital technology. He characterises three main dynamics of the current music industry: connectivity versus control, service versus product and amateur versus professional (Ibid., 5-9). He identifies eight digital business models: single song download; membership - limited download quota; membership - all- you-can-eat; ad-based models; value-based pricing models; bundling music with other media products; mobile music; and to service, or not to service (Ibid., 101-117). Similarly, Stephen Bradley, Kim Changsu, Kim Jongheon and Lee In propose five evolution strategies for the digital goods business (DGB) ${ }^{3}$ to cope with the changing environment of digital technology: from streaming direct to streaming intermediary; from download direct to download intermediary; from download intermediary to streaming intermediary; from download direct to streaming direct; and from download direct to streaming intermediary (Bradley et al. 2012).

Furthermore, Anandhi Bharadwaj, Omar A. El Sawy, Paul A. Pavlou and N. Venkat Venkatrman employ the term 'Digital Business Strategy' to address the development of information, communication and connectivity technologies over the last three decades. They use this term to indicate a fusion between information technology strategy and business strategy, which they argue is a possible model to reshape traditional business strategy in the new digital era. They propose four key themes as a framework for their discourse of digital business strategy - the scope of digital business strategy, the scale of digital business strategy, the speed of digital business strategy and the sources of business value creation and capture (Bharadwaj et al. 2013). Also, Jens Leth Hougaard and Mich Tvede discuss the future structure of the music market. They argue that the consequences of digitalisation and the peerto-peer (P2P) networks alter music as non-excludable goods. They discuss six various model of selling music: the mechanism design model; the Disney model; the game console model; the bundling with private goods model; the

2 The term 'virtual' is used to indicate the digital form of music content. The term 'virtual' is also used to refer to cloud where Wikström defines cloud as internet and the current model of music business created by the new digital technology.

3 DGB is referred specifically for digital music in this paper. 
eyeball model; and the open source model. The authors suggest that the last two, 'the eyeball model' and 'open source model,' are the appropriate models for the current music industry (Hougaard \& Tvede 2010). Moreover, Gal Oestreicher-Singer and Lior Zalmanson discuss social computing as a possible model for a digital business strategy in a digital world (Oestreicher-Singer \& Zalmanson 2013). Tom Ewing discusses a case study of ILX, ${ }^{4}$ pointing out that the web community could be a potential model for the digital music business (Ewing 2008), while Manuel Sanchez-Franco and Francisco J. Rondan-Cataluña focus on how online music services should consider customer emotions in addition to their satisfaction and trust to maintain an authentic relationship (Sanchez-Franco \& Rondan-Cataluña 2010).

Several case studies around the word have been carried out to address digital technology and its impact in the music industry. Muhammad Maraghah conducted an in-depth study of the Egyptian music industry to investigate the impact of new digital technologies and their developments. He examines the Egyptian music industry's current situation and analyses the role and significance of new digital technologies with regard to their adaptation for creating an optimal business model for sustainable income in the Egyptian music industry. He proposes a Digital Arabic Repertoire and Network Aggregator for the Independent Egyptian Music and Independent Arabic Music industries as a future business model in the digital era (Maraghah 2013). Similarly, Dina Dellyana and Togar M. Simatupang's research explores some available business models including Ring Back Tone (RBT) and mobile music, and their role in the Indonesian music industry. They also discuss licensing models ${ }^{5}$ and entertainment models $^{6}$ as new sources of income in the Indonesian music industry (Dellyana \& Simatupang 2014). A process model for creating an independent business as opposed to signing with label - such as Melodic Twilight project for an Indie Canadian artist (Pettipas \& Jagoda 2012) - and a study of consumers' behaviours and habits on Brazilian Internet users for customer-oriented marketing action (Martins \& Slongo 2014) are some more case studies carried out on music digitisation.

The Norwegian music industry is one of the most successful and sustainable music industries adapted to the digital music business model. According to Daniel Nordgård, the Norwegian music industry has adopted subscriptionbased, on-demand streaming. He argues that subscription-based streaming is a sustaining innovation, rather than disruptive, in the Norwegian music industry (Nordgård 2014). The Norwegian music industry's journey from a traditional business physical model to a digital music business has seen an upward trend over the last 5-7 years. Initially, it entered into the digital marketplace using digital sales including downloading and streaming, which was $9.3 \%$ of total music sales. Gradually, it rose and reached at $61.4 \%$ in 2012 . It showed continuous growth and reached $77.6 \%$ of total market sales in 2013 , which indicates that digital music business is taking over the physical market and becoming a sustainable business model. As streaming is a major source of revenue, it holds a $65 \%$ stake in the total Norwegian music market. Total digital sales including downloads and streaming increased by $40 \%$ from 2012 to 2013 (Music Norway 2019). The International Federation of the Phonographic Industry's (IFPI) 2014 digital music report reveals that $75 \%$ of total digital revenues in Norway accounted for subscription streams, whereas $11 \%$ was from permanent downloads (IFPI 2015). According to IFPI Norge, Norway is at the top in the world in digital music consumption. Its report reveals that revenue from streaming increased by 28 million $\mathrm{Kr}$ in the first half of 2014 to first half of 2015 . Music sales grew $6.5 \%$ from the first half of 2014 to first half of 2015 and reached $81 \%$ of music sales (IFPI Norge 2019).

While some scholars believe that new digital technology is a positive turning point for the music industry and suggest various new strategies and models for the digital music business, others argue that digital technologies have had a profound negative impact on the music industry. François Moreau calls digital technology's impact on the recorded music industry a 'disruptive' phenomenon (2013). Dagfinn Bach also claims that there are environmental risks and problems caused by the rapid growth of current digital content industries and its data traffic (2012). Similarly, Peter Jenner and Mathew Brown discuss digital technologies' implications and use the term 'earthquake' as a metaphor for its consequences for the global music industry. Jenner and Brown discuss the changing relationship between artists, fans and consumers in the music business as a result of digital technologies and refer to it as a serious music industry debate (Jenner \& Brown 2006). Furthermore, Robert G. Picard comments that access to digital technology, for instance with the internet, has generated a huge threat of theft, infringement and illegal use of creative contents (Picard 2004). Other scholars such as Harlan Spotts note that the result of the illegal downloading

$4 \quad$ ILX (iXlor.com) is an internet forum (message board) site for people with similar interests for discussion. "I Love Music" is one board of ILX forum for a music conversation that the author defines as a community and indicates a potential model for digital music business.

5 These models involve providing a license for a music catalogue to a particular company or brand for a certain period of time.

6 The record company also runs the event organiser and artist management deal. 
and file-sharing phenomenon is a serious problem for the music industry and has disrupted the business model for the creation and distribution of music (Spotts 2010). Karla Borja, Suzanne Dieringer and Jesse Daw's findings reveal that music streaming increases the probability of people committing music piracy by about $20 \%$ (Borja, Dieringer, \& Daw 2015). Oscar F. Bustinza, Ferran Vendrell-Herrero, Glenn Parry and Vasileios Mysthianos show that $28.2 \%$ of the population participates in illegal file sharing. Their 2010 study evaluates the degree of illegal file-sharing activity among 44,000 consumers across ten countries: Spain, The Netherlands, Italy, Canada, USA, Australia, France, UK, Japan and Germany (Bustinza et al. 2013: 4-22). Furthermore, Peter S. Menell, Andrew E. Burke and Jukka Liedes underline the significance and indispensability of copyright legislation in the digital world (Menell 2013; Liedes 1997; Burke 1996). Eleanor R. E. O'Higgins and Steven Bonner's study finds that the active music fans are more likely to resort to illegal downloading; and Adrian Adermon and Che-Yuan Liang's findings show the slow legal processes encourages illegal file sharing (Adermon \& Liang 2014). Joel Waldfogel points out the issues of copyright protection on music content and the need to research it further in the digital age (Waldfogel 2012).

In contrast, some scholars dispute the negative views on digital technology and music digitisation. Homayoun Derakhshanno argues that fighting with the file-sharing phenomenon is futile (Derakhshanno 2009). Likewise, G. Heath emphasises that consumers will pay for music if the offer is attractive, such as using iTunes as an example of a successful service provider (Heath 2013). Independent Music Companies Association (IMPALA) statistics shows that $61 \%$ of internet users in Europe are legitimate music consumers (IMPALA 2019). Martin Kretschmer also disputes the defensive nature of the record industry toward digital development and evaluates its possible threat to the future music business and creative activities (Kretschmer 2001). Similarly, Bart Cammaerts, Robin Mansell and Bingchun Meng's findings concur with Kretschmer, demonstrate potential revenue growth in the music industry from the new streaming and subscriptions business models and suggest adapting to the digital environment earlier (Cammaerts, Mansell, \& Bingchun 2013). Waldfogel argues that piracy is not only the ultimate cause for the sharp decline of music industry revenue (Waldfogel 2012). Mehmet D. Delikan's finding suggests the positive effects of streaming music services on decreasing music piracy (Delikan 2010). Tim P. Thomes' analysis suggests the streaming business model can be effective in preventing digital piracy (Thomes 2013). Olufunmilayo Arewa's study examines developing approaches for sustainable business models in the digital era. The study suggests that considering the needs of the users, reviewing the pricing model, and avoiding treating users as thieves, could be significant factors in successfully tackling the challenge of the digital era (Arewa's 2010). According to Nordgård, the music industry either has to adopt the technological developments or disappear. He says that new digital technology and its impacts are inevitable, and it is rational to adopt new digital business models (Nordgård 2014).

\section{The Nepalese Music Industry: Current Structure, Business Models and Revenue Sources}

Nepal is a linguistically and culturally diverse country. Modern day Nepal as a state emerged in the late eighteenth century after the unification of several small kingdoms into a single country (Whelpton 2005). During the period of the Shah Dynasty and the hundred years of Rana's reign, music was limited to within the palaces, and common people did not have access to play and listen to music. Music was introduced publicly after the advent of Radio Nepal in 1950, providing the opportunity for Nepalese citizens to listen to music (Greene \& Henderson 2000). In addition, it created possibilities for recording songs. In 1908, Setu Ram Shrestha was the first Nepalese recording artist who set the trend of music recording in the Nepalese music industry. The trend was followed by several other famous artists (Subedi 2019). Until 1971, Nepalese artists used to travel to India to record their songs. The Nepalese recording industry emerged when the government-supported Ratna Recording Corporation was established in the capital of Nepal, bringing significant change to the Nepalese music industry. The introduction of television in late 1970 and private film production in 1975 also put tremendous effort into the growth of the Nepalese music industry (Kasajoo 2008).

Nepalese music began to take the form of a business beginning with the production of vinyl records from stateowned Ratna Recording Corporation. Subsequently, the audio cassette format was introduced. It displaced vinyl and became a major source of music business until the late 2000s. Later, when the CD was introduced, it replaced audio cassettes completely. CDs are still the current major legal music business in the Nepalese music industry and there are over a hundred studios in Nepal working with music recording and distribution (Subedi 2019). Almost every day, 
CDs of new music albums are released. According to Kasajoo, the Nepalese music industry is estimated to have an annual business of over four million US Dollars (Kasajoo 2008). The private sector of the music industry started to grow from 1980, and in the last 15 years commercial folk music 'lok dohor' has gained tremendous popularity.

The biggest revenue source for the Nepalese music industry is becoming the RBT model. RBT is popular in two different sub-models: the personal ring back tone (PRBT) and the caller ring back tone (CRBT). According to the report from Himalayan Television, this model is generating around 410,000 US Dollars in annual revenue for the Nepalese music industry today. Former president of the Association of Music Industries Nepal (AMIN) Padam Bahadur Buda says that RBT is one growing revenue source for the Nepalese music industry and it is making a significant contribution, generating revenue from six or seven Gulf countries (Nepali Banknews 2012). Also, local and international live music shows are a vital revenue source for the Nepalese music industry today in the context of the decline of albums sales and less revenue from music companies and RBT service providers. Local concerts in Nepal and especially international concerts organised by the Nepalese diaspora are generating significant revenue for the artists and music industry (Image Channel 2013). CDs and Video CDs (VCDs) used to be one major source of revenue for the Nepalese music industry and remain an important source of revenue for artists and music companies, but the ratio has dropped dramatically in recent years. At one time CDs and VCDs dominated the music market, with more than 200,000 units sold annually, but that figure is in the hundreds now. The CD/VCD business is a dying business in Nepalese music industry. The revenue from YouTube is not visible in the Nepalese music industry; however, it is expected to be one of the potential revenue sources in the near future. In recent years, YouTube channels have been growing in the Nepalese market for promotion and marketing purposes (Nepali Banknews 2012).

The Nepalese music industry's current business market is divided into three different genres: commercial folk music (lok geet, Dohori geet) holds $50 \%$ of the market; modern songs (adhunik geet) holds $25 \%$; and the remaining $25 \%$ is shared by pop music and various regional and linguistic songs (Nepali Banknews 2012). The technological changes have caused many established record companies to go bankrupt, and very few have sustained their businesses. Among them, Music Nepal is the oldest and biggest. It was established in 1982, and currently holds one third of the whole market (Music Nepal 2019). Other active and growing music companies are Bindabasini Music, Budha Subbha Music, Ranjana Music, SAC Music, Santana Records and Rebel Entertainment. Before the emergence of new digital technology, the Nepalese music industry used to make millions of business transaction through audio cassettes, CDs and VCDs. More than 10,000 people were employed and involved in the music business directly and indirectly. But now the sales of more than 200,000 cassettes and 50,000 CDs and VCDs has fallen to the hundreds and continues to decline daily; the production and sales of cassettes has almost stopped; and CD sales have been greatly impacted by duplicate copies and piracy (Nepali Banknews 2012).

\section{Situating Nepalese Music Market within Neighbour Music Industry: An Analytical Perspective}

Nepal is a landlocked central Himalayan country in South Asia. It shares borders with China in the North and India in South, East and West. It is often called a sandwich between two giant neighbours. Socially, culturally and politically, Nepal shares many commonalities with both of its neighbours; however, its sociocultural system is predominantly similar to India. Concentrating on music culture - dialects, musical instruments and music repertoires - Nepal's north-eastern part where mainly Sherpa-dwellers live is largely influenced by the music and culture of Tibet's Trans-Himalayan region (Kaufmann 1962). Although mountaineering is the Sherpas' major occupation, Sherpas' recordings are a notable presence in the Nepalese recorded music market during recent decades. Similarly, other ethnic groups such as Newar, Gurung, Tamang, Magar, Maithili and so forth have had their ethnic and regional music introduced in a media form after the 1950s because Radio Nepal, a national radio station, was established under the one-party Panchayat government to promote musical nationalism. Several music competitions and festivals helped to promote this regional and ethnic music, but later the overthrowing of the Panchayat government in 1990 brought liberalisation and pluralisation to media and music and helped this music develop as a form of niche market (Stirr 2017: 29-51).

Apart from the regional and ethnic music market, the mainstream Nepalese music market is greatly influenced by Indian music culture. Carol Tingey traces Nepalese music history and connects it with Indian music as far back as the 14th-15th centuries; various music ensembles such as nagara bana (kettledrum ensemble), which King Akbar used as a symbol of royal power in the Indian court, were brought from the Rajput settlers of Indian 
during the 14th to 15th centuries. This ensemble has become indispensable in Nepalese society today (Tingey 1990), where Indian music culture is even more evidently visible and deeply embedded in Nepalese lives. Janet Sturman Says:

"The music of Nepal, a nation located in the shadow of the Himalayas, represents Indian, Islamic, Tibetan, and Nepali music traditions [...]. Indian classical music and musicians played a role in Nepali courts and among the upper castes" (Sturman 2019: para 3).

Like Sturman, several other scholars have noted the influence of Indian styles such as Hindustani classical and semi-classical in Nepalese music, mainly Adhunik geet (modern songs) that was tremendously popularised after the advent of electronic media in the Nepalese music industry. It used to take up more than half of the market before the civil war elevated rural migration, which led to the rural-originated genre dohori (dialogic, conversational sung poetry) changing the market trend (Henderson 1996; Green and Henderson 2000; Grandin 2005, Stirr 2017).

Furthermore, Bollywood music is another favourite choice for Nepalese audience. Bollywood artists travel to various parts of Nepal, mainly the capital city Kathmandu, almost every month for the purpose of live concerts. During the period of 2015-2019, several well-known and popular celebrities from Bollywood such as Sonu Nigam, Sonakshi Sinha, Himesh Reshammiya, Farhan Akthar, Neha Kakkar, Kailash Kher and Aditya Narayan visited Nepal for live concerts. Additionally, the Nepalese film market is heavily dominated by Bollywood films (Global Times 2012; Pathak 2017: 167-177). Aljazeera says: '[...], 80\% of Nepal's film market is dominated by Bollywood, the world's largest film industry that churns out 1,000 films annually compared to 95-100 films released domestically' (2014). Bollywood films get released every week and occupy most of the big and popular cinema halls of Kathmandu and other major cities. Not only has Indian music and film dominated the Nepalese market, but so has the entire Indian entertainment industry, as evidenced by the significant presence of Indian music, TV shows, movies and live concerts in national and private media platforms. Certainly, digital technologies have become a powerful tool to develop this hegemony, but other factors such as open borders and similarities between culture and language are crucial factors for this dominance.

Comparatively, the Nepalese music market is considerably smaller than its neighbours in India and China. According to the 2019 IFPI report, the Chinese music market is ranked as the 7th largest music market in the global music market (2019). It made a dramatic shift from 12th to 7th place in 2 years. The Chinese music industry is mainly using the streaming model, with it generating 70\% of the recording revenues in 2017 (Soundcharts 2019; Musically 2018). Similarly, India shows great potential to become a leading music market in Asia with an increase of $60.8 \%$ in streaming revenue in 2018 (IFPI 2018), ranking as the 19th largest global music market in 2016 (Music BC 2017). The Indian music industry entered into the streaming business in recent years but based on its dramatic increase in digital growth both in mobile channels and streaming, reports suggest that it will become a top 10 global market in the near future (Ibid.; IFPI 2020; Music Business Worldwide 2019; Livemint 2018). IFPI says:

"India's mobile phone market grew hugely in 2006 and has since gained more than half billion subscribers, taking the total today to 900 million. Music plays a key role in mobile operators' customer acquisition, branding and engagement strategies, as smartphone adoption rises. Leading operators such as Airtel, Vodafone, Idea and Tata Docomo offer a range of music services including ringtones, ringback tones, downloads and mobile radio streaming services - which are usually bundled into subscription packages" (IFPI 2020).

Similarly, Forbes writes:

"IIndia] recently surpassed the U.S. as the world's second-largest smartphone market, which is estimated to reach 450 million users by 2020. Moreover, $96 \%$ of these phones are expected to be manufactured domestically, which has directly ties to music streaming: three of India's largest streaming services - Jio Music, Wynk Music, and Gaana-are run by local telecom and internet companies (Reliance Jio, Bharti Airtel, and Times Internet, respectively)" (Forbes 2017).

Based on Indian and Chinese digital music business data, mobile music is one of the significant revenue sources in the Indian music market, whereas the Chinese music market predominantly uses the streaming model. After the development of digital technologies, the Indian, Chinese and Nepalese music industries faced similar issues of illegal file sharing, downloads, piracy and huge decline in physical sales. However, India and China embraced digital 
technologies and looked for the optimal route to sell their music. In the case of the Indian music market, it developed local music downloading and streaming apps such as Gaana, Hungama and JioMusic that collaborated with the telecom services. Similarly, Saavn, Wynk and several other streaming and downloading services are working for music customers. Currently, in the Indian music market, $85 \%$ of online music is consumed through smartphones (Music BC 2017). Despite the significant number of mobile and smart phone users in Nepal, the music industry presently is not able to address the digital music business' needs. Apart from RBT and PRBT, there is no other legitimate model currently in the Nepalese music market for the digital music business despite the huge influence of the Indian music industry. Whilst its neighbouring music markets are heading to the race of global leading music markets with formidable development and growth in their digital music businesses, the Nepalese music industry is failing to find a path to replace the dying physical music business.

\section{Digital Music Business: Challenges and Opportunities for the Nepalese Music Industry}

The Nepalese music industry was in decent form during the era of cassettes and CDs. The emergence of new digital technology is the only factor responsible for the destruction of the whole industry. In consequence, thousands of people lost their jobs, many artists abandoned the industry, record companies were forced to shut down, consumers turned to illegal users, music became free in the cloud and the industry lost its business. RBT and YouTube are the only two media the industry is using to provide music in a legal digital form. RBT service provided integration between the music industry and telecom services. YouTube has generated some additional revenue and music companies are publishing their content as a free service to the consumers. Music industry executives eventually accepted that there will be no revival of the physical market.

From the interviews conducted with executives and stakeholders of different major, medium and independent Nepalese record labels, six out of eight executives strongly recommend the alternative business model to digitise and make Nepalese music available on international platforms and the local market. Two express their preference to create an alliance and act as leaders in the Nepalese music industry because they have a huge collection in their catalogue and have access to global platforms. In contrast, six expressed their consent and seemed to welcome an alternative digital music aggregator in the Nepalese music industry. One of the executives says, 'We are very positive about that [digital music business] opportunity. In fact, we are looking for the kinds of possibilities where some new aggregator arrives and gives us new hope and new possibilities. We are very positive for the new entrants' (Executive III, indie record label).

They are much more interested in the alternative model and are willing to hand over their content if a decent offer is made from any alternative source. Another executive says, 'If anyone can help us to reach to these international digital platforms directly and we can provide our music content to them directly, we are always welcome [to] that opportunity' (Executive II, major record label). They express their enthusiasm for the urgent need of an alternative model. They also express their willingness to work in a business environment where they can approach new opportunities and grow their businesses. One executive adds, 'Definitely, if there is some convincing opportunity where we can work and grow our business, we are very positive about the alternative. Not only us, [but] many of the stakeholders are looking for such opportunities' (Executive I, indie record label). Most of the interviewees, particularly from the medium and small sized record labels, say that they are compelled to adopt and adhere to the traditional models because their labels are unknown, and they do not know how to obtain global access. One executive describes the situation: 'We do not have any general idea about how to reach to them. If we have any access for that we will consider it as our opportunity and path to introduce Nepalese music in global music market' (Executive IV, indie record label).

In the context of making the digital Nepalese repertoire locally available, most interviewees indicate telecoms as the best potential avenue. They report that the use of telecoms and mobile phones has increased significantly. There are currently six telecom companies providing service in Nepal. Mobile telephone represents $94 \%$ of the whole telecom market and the remaining $6 \%$ is taken by fixed telephone services and others. The major market share is split between private mobile company Ncell (40.42\%) and state-owned telecom company Nepal Doorsanchar Company Limited (57.15\%), while the rest are taken from various companies (Nepal Telecommunications Authority 2015). They point out that working together with telecom companies would be the best option to provide legitimate digital content in the local market. One executive says, "If we collaborate with telecom services and create the 
environment to provide customers full songs and videos, [then the] future of Nepalese music business is positive' (Executive III, indie record label). Similarly, another executive adds, 'The potential opportunity regarding the current scenario is integration with telecom services to reach to the potential consumers with open access and open competition within the record labels' (Executive I, medium record label). Majority of the interviewees reveal their desire to work with possible alternative models to reach the global market. They emphasise access and networks as essential aspects for the digital music business, locally and internationally.

As new technology has arrived, the Nepalese music industry has undergone dramatic changes. There is not much investment in records. Most of the interviewees say that the industry structure is altering from physical to digital mode. Through the entire interview session only one topic is constantly replicated - the urgent technological requirements of the Nepalese music industry. Below, a few of the executives recount their technological concerns:

"Everything has changed with the technology and our traditional knowledge does not work. It is urgent to have knowledge now [of] how new things are going in the music industry; how [the] digital arena works and how to make [the] best use of those available platforms" (Executive I, major record label).

"The major drawback in Nepalese music is that we are behind to employ technology. We only know how to produce an album and that is it. Even 5\% of us do not have knowledge of how to make it available in global platforms and how to approach the global digital network. In fact, the Nepalese music market is growing but we are lacking the knowledge and network" (Executive IV, indie record label).

"Lack of technological acceptance and our insufficient marketing strategies are major problem in our music industry. The reason behind our slow progress is technology. We do not have instant and sustainable access to internet. We couldn't employ the advantages of technology and we lack knowledge to use these new technologies" (Executive III, indie record label).

They characterise technology as the major challenge for the development of the industry. Medium and small record labels are more concerned with technological requirements and knowledge. Further, they explain that lack of access to international digital platform, inadequate training and knowledge of digital technologies and lack of human and technical resources are major factors preventing the legal digitisation of the Nepalese music.

In the context of new digital technology and its application in digital music distribution in the Nepalese music industry, two theories from W. B. Arthur and Joseph Schumpeter should be introduced. Arthur says, 'More than anything else technology creates our world. It creates our wealth, our economy, our very way of being' (Arthur 2009: 10). He believes that technology is a method, process or device to fulfil a purpose. He defines the economy 'as the set of arrangements and activities [with] which a society satisfies its needs' (Ibid., 192) and calls technology a skeletal structure of economy. He believes that the economy changes when its technologies change. His theory of evolution for technology aligns with Joseph Schumpeter's discourse of 'new combinations of productive means in economic change' (Ibid., 15-26). Schumpeter's theory argues that economic development is a phenomenon which alters and displaces the previously existing system of economy, where mechanisms of circular flow work as the major driver to maintain the equilibrium position in the existing economic system or life. The key driver of change in the traditional or existing economy is carrying out new combinations '[e]specially in a competitive economy, in which new combinations mean the competitive elimination of the old' (Schumpeter, 2012: 67). Schumpeter coins the term 'new combination' as innovation.

Based on these characteristics of innovation, music digitisation and the digital business can be considered new combinations in the music industry. While adhering to Schumpeter's theory, the Nepalese music industry is in a position where it needs to employ new combinations in adopting digital music. The shrinking revenue and dying market of the physical music business, which can be termed as circular flow or the old economic system from Schumpeter's theory, need to be replaced. This new combinations' innovation may change the face of the Nepalese music industry and enhance the economic development of the entire industry. Similarly, as Arthur describes technology as a method, process or device to fulfil a purpose, his definition of technology can be employed to examine how technology can harness the economic development of the Nepalese music industry.

In the context of understanding the challenges and discussing the potential legitimate music distribution model for the Nepalese music industry, an overview of some popular models is worthwhile to discuss. Many download models have been developed and implemented to sell the music digitally to customers. Apple's iTunes started 
providing music to the consumers legally in 2003, employing the "Single Song Download Model". Later, in 2007, Amazon entered into the single song download model market. Another model, which is employed by iTunes and Amazon, is the 'Membership Download Model' providing music to download depending on a membership (Wikström 2009: 101-103). Music streaming is the second most successful model in the digital music market. It has two variants: subscription streaming and ad-supported streaming. Music subscription is becoming a major driver for the growth of the digital music revenue. According to the IFPI, revenue derived from subscription streaming accounts for more than half $(58.9 \%)$ of the global recorded music market. The streaming increased by 34\% in 2018 (IFPI, 2019 ). Research findings from Ipsos Media CT for IFPI shows $74 \%$ of consumers use streaming sites, whereas $73 \%$ prefer downloading sites. Some countries, including Germany, Austria, Canada and the USA, favour downloading models. The streaming model is popular in Sweden, South Korea, Norway and Finland (IFPI 2015).

As downloading and streaming have already gained a foothold in the digital business market, music video and the internet radio models have also sought the marketplace in the digital world. For instance, VEVO and YouTube are increasingly attracting global audiences and generating significant revenue from advertising. Watching online music videos is becoming popular for music consumers. Consequently, the music video model is a substantial revenue source for the music industry in the digital music market. For example, Psy's 'Gangnam Style' has been watched more than one billion times on YouTube. Secondly, a huge number of consumers are engaging with internet radio, which is serving music consumers using a customised playlist of specific artists or genres, with various options for the listeners to manipulate. This model is mostly popular in the USA, with such internet services as Last.fm, Pandora and iHeartRadio. Bundling strategies are quite popular and common in every business sector. Music also can be sold using such strategies through newspapers, magazines, mobile devices and several other products. Wikström illustrates some of the common examples, such as the collaboration between the Irish rock band U2 and Apple, and the extensive bundling program 'Comes With Music' offered by Nokia mobile manufacturer (Wikström 2009). Because mobile telephony is a basic need for people today, the collaboration between record labels and mobile telephone companies can generate huge revenue. For instance, in South Korea the mobile telephony company SK Telecom has more than twenty million subscribers and it is integrating with the major record label and music distributor JYP Entertainment and Seoul Records. In addition, SK Telecom operates the country's largest online music service 'MelOn' with more than four million basic subscribers and 600,000 premium subscribers who pay $\$ 5$ monthly fee with unlimited music offer (Ibid.).

Based on the foregoing discussion on the current legitimate digital music business trends and models created by the innovation of new digital technologies, scrutinisation of neighbouring music markets, overview of popular digital music distribution models, study of relevant theories and discourses and information from the interviews, the findings from the research study can be summarised in seven key points:

1. The current market is greatly affected by the massive downturn of the physical music business. The RBT music model is failing and the YouTube model is not generating significant revenue for the medium and indie record labels. Other sources of revenues do not provide adequate support for the industry. A legitimate digital music business can be one viable music business model in the current circumstances.

2. Inadequate technological resources, knowledge, training and skills are major impediments to digitising music. The lack of international contacts, networks and knowledge of how to reach to digital services are barriers preventing a legal digital music business in the Nepalese music industry.

3. The majority of record companies are willing to work with the alternative business model rather than the existing ones and are ready to provide their content. They want to make their content available to international digital platforms, but they do not know what to do or whom to contact.

4. Integration with telecom services to enhance and develop RBT services into a song's full content for downloading and streaming could be a potential opportunity for the local digital music business.

5. Online banking could create options for digitally buying music. The current banking system does not provide online banking and so is preventing this service.

6. The stakeholders find that there is no profitable environment for further investment in record production, which has suffered from the illegal market. The enforcement of copyright and intellectual property rights is ineffective, and there is no monitoring body.

7. Stakeholders are exploited by existing mechanisms in the music industry. They are compelled to provide content to telecom services, where it is used in several other digital services without their knowledge, and they receive no remuneration. The industry greatly lacks transparency and a monitoring body. 


\section{Conclusion}

Andrew Blum says that the internet is a culture and a medium (Blum 2012). Today, the world stores things in a cloud. Global music is becoming digital. New digital technology is transforming the music industry into a rapidly growing digital marketplace. Although the global music industry is shifting its structure towards digitisation, the Nepalese music industry is failing to adapt to the digital music business model. In this paper, the key reasons for the barriers to a digital music business and its prerequisites, challenges and feasibilities in the Nepalese music industry are investigated.

The result of this study identifies that the Nepalese music industry is not able to provide legal digital music services to consumers as it lacks adequate technological resources that would enable the industry to enter into the legal digital market. In addition, international access and networks are ineffective. Another factor encouraging the illegal market is the unavailability of legal services for legitimate music distribution services. Record companies do not have adequate technical and human resources, or the skills and knowledge for digitising the music. The banking system has also created potential barriers for digital financial transactions. Furthermore, this paper identifies the need for a legitimate digital music business in the current Nepalese landscape to resolve the problem. The results from the secondary data also support the major findings from the interviews. With close examination of the research problem, an overview of different available models, and insight from neighbouring music markets and the interviews with executives, the establishment of the Umbrella Aggregator and Network for Digital Nepalese Repertoire (UANDNR) could be a feasible digital business model to transform the current Nepalese music industry into a legitimate digital music business.

\section{Author Biography}

Subash Giri is an Assistant Lecturer of Indian Music Ensemble (IME) at the Department of Music, University of Alberta. He is also a Ph.D. Candidate of Ethnomusicology. He holds three master's Degrees in Music Management (M MUS MGMT) from University of Agder, Norway, Hindustani Classical Voice (M MUS) and Sociology (MA) from University of Nepal. His research focuses on South Asia, particularly on Nepal and India. His research articles have been published in several international journals.

\section{References}

Adermon, A. \& Liang, C.-Y. (2014) "Piracy and Music Sales: The Effects of Anti-Piracy Law", Journal of Economic Behavior and Organization, vol. 105, pp. 90-106.

Aljazeera (2020) "Nepal's film industry looks beyond Bollywood". Available at https://www.aljazeera.com/indepth/ features/2014/07/nepal-film-industry-looks-beyond-bollywood-2014714104224592144.html (January 25, 2020).

Arewa, B. O. (2010) "YouTube, Ugc, And Digital Music: Competing Business And Cultural Models In The Internet Age", Northwestern University Law Review, vol. 104, no. 2, pp. 431-475.

Arthur, W. B. (2009) The Nature of Technology: What It Is and How It Evolves. Free Press, New York.

Bach, D. (2012) The Dark Side of The Tune: The Hidden Energy Cost of Digital Music Consumption, Music Tank, UK.

Bharadwaj, A., Sawy, O. A., Pavlou, P. A. \& Venkatraman, N. (2013) "Digital Business Strategy: Toward A Next Generation of Insight", MIS Quarterly, vol. 37 no. 2, pp. 471-482.

Blum, A. (2012) Tunes - Behind the Scene at the Internet, Penguin Group, 80 Strand, London WC2R ORL.

Borja, K., Dieringer, S. \& Daw, J. (2015) "The Effect of Music Streaming Services on Music Piracy Among College Students", Computers in Human Behavior, vol. 45, pp. 69-76.

Bradley, S., Kim, C., Kim, J. \& Lee, I. (2012) "Toward An Evolution Strategy for the Digital Goods Business", Management Decision, vol. 50, no. 2, pp. 234-252.

Burke, A. E. (1996) "How Effective International Copyright Conventions in the music Industry?" Journal of Cultural Economics, vol. 20, no. 1, pp. 51-66.

Bustinza, O. F., Vendrell-Herrero, F., Parry, G. \& Mysthianos, V. (2013) "Music Business Models and Piracy", Industrial Management and Data System, vol. 113, no. 1, pp. 4-22. 
Cammaerts, B., Mansell, R. \& Bingchun, M. (2013) "Copyright and Creation: A Case for Promoting Inclusive Online Sharing", LSE Media Policy Project, pp. 1-18.

Delikan, M. D. (2010) Changing Consumption Behaviour of Net Generation and the Adoption of Streaming Music Services: Extending the Technology Acceptance Model to Account for Streaming Music Services, Master Thesis, Jönköping International Business School.

Dellyana, D. \& Simatupang, T. M. (2014) "Existing Music Business Model in Indonesia in Search of New Income Source", Procedia - Social and Behavioral Sciences, vol. 115, pp. 407-414.

Derakhshanno, H. (2009) Future of the Music Industry: A Holistic View on Positive Effects of P2P File-Sharing, Master's Thesis, School of Science and Communication Royal Institute of Technology, Stockholm.

Ewing, T. (2008) "Participation Cycles and Emergent Cultures in an Online Community", International Journal of Market Research, vol. 50, no, 5, pp. 575-590.

Forbes (2017) "How India, The Global Music Industry's Sleeping Giant, Is Finally Waking Up". Available at https:// www.forbes.com/sites/cheriehu/2017/09/23/how-india-the-global-music-industrys-sleeping-giant-is-finallywaking-up/?sh=48c83b1530bf (January 24, 2020).

Global Times (2012) "Nepali Movie Industry Struggles under Shadow of Bollywood". Available at http://www. globaltimes.cn/content/749977.shtml (January 25, 2020).

Grandin, I. (2005) "The Soundscape of the Radio: Engineering Modern Songs and Superculture in Nepal", in Wired For Sound, eds. P. Green \& T. Porcello. Wesleyan University Press, Middletown, pp. 222-244.

Greene, P. D. \& Henderson, D. R. (2000) "At the Crossroads of Languages, Music and Emotion in Kathmandu", Popular Music and Society, vol. 24, no. 3, pp. 95-116.

Heath, G. (2013) "A Time for Change". Music Week, New Bay Media, 19 July, pp. 17.

Henderson D. (1996). "Emotion and Devotion, Lingering, and Longing in Some Nepali Songs", Ethnomusicology, vol. 40 , no. 3 , pp. $440-468$.

Hougaard, J. L. \& Tvede, M. (2010) "Selling Digital Music: Business Models for Public Goods", Netnomics, vol. 11, no. 1, pp. 85-102.

IFPI (2015) IFPI Digital Music Report 2015, IFPI.

IFPI (2018) IFPI Global Music Report 2018, IFPI.

IFPI (2019a) "Engagement with Streaming Drives Growth of Global Music Market". Available at https://ifpi.org/factsand-stats.php (August 7, 2019).

IFPI (2019b) IFPI Global Music Report 2019, IFPI.

IFPI (2020) "Around the World: India". Available at https://www.ifpi.org/india.php (January 29, 2020)

IFPI NORGE (2019) "Musikk i tall - Halvårstall 2015". Available at http://www.ifpi.no/flere-nyheter/item/98(August 7, 2019).

Image Channel (2013) E-MAG-Ringback Tone (CRBT/PRBT/RBT) Report-Nepali Music Industry. Image Channel, Kathmandu.

IMPALA (2019) "European Music in Numbers". Available at: http://www.impalamusic.org/node/9 (August 10, 2019). Jenner, P. \& Brown, M. (2006) Beyond the Soundbytes, Music Tank, UK.

Kasajoo, V. (2008) "Communication Scenes Nepal", in Asian Communication Handbook, eds I. Banerjee \& S. Logan, Asian Media Information and Communication Centre (AMIC) and WKWSCI-NTU), Singapore, pp. 335-355.

Kaufmann, W. (1962) "The Folksongs of Nepal”, Ethnomusicology, vol. 6, no. 2, pp. 93-114.

Kretschmer, M. (2001) "In Defense of Piracy: Music Copyright and Creativity in the Digital Environment", Micazine, pp. 1-5.

Liedes, J. (1997) "Copyright: Evolution, Not Revolution. Science”, New Series, vol. 276, no. 5310, pp. 223-225.

Livemint (2018) "Indian Music Industry Grows $24.5 \%$ in 2018”. Available at https://www.livemint.com/industry/media/ indian-music-industry-grows-24-5-in-2018-1554215051388.html (January 29, 2020).

Maraghah, M. (2013) The Future of the Independent Egyptian Music in the Digital Era, Master Thesis, University of Agder, Kristiansand.

Martins, J. P. \& Slongo, L. A. (2014) "The Digital Music Market: A Study of Bralizian Consumers' Behaviour”, Review of Business Management, vol. 16, no. 53, pp. 638-657.

Menell, P. S. (2013) This American Copyright Life: Reflections on Re-Equilibrating Copyright for the Internet Age, Copyright Society of the U.S.A, United States, pp. 1-134.

Moreau, F. (2013) "The Disruptive Nature of Digitization: The Case of the Recorded Music Industry", International Journal of Arts Management, vol. 15, no. 2, pp. 18-31. 
Music BC (2017) India Music Market Study, Music BC.

Music Business Worldwide (2019) "India's Music Business Will Almost Double in Value By 2019 - KPMG". Available at https://www.musicbusinessworldwide.com/indias-music-business-will-double-by-2019-kpmg/ (January 29, 2020).

Music Nepal (2019) "About Us" Available at https://www.musicnepal.com/index.php/about-us/ (August 10, 2019).

Music Norway (2019) "Streaming Fuels Growth on Home Market". Available at https://musicnorway.no/2016/09/27/ streaming-fuels-growth-home-market/ (August 10, 2019).

Musically (2018) "China's Music Potential: We are Finally Getting There!" Available at https://musically. com/2018/05/22/chinas-music-potential-we-are-finally-getting-there/ (January 30, 2020)

Nepal Telecommunications Authority (2015) MIS Report, Nepal Telecommunication Authority, Kathmandu.

Nepali Banknews. (2012) Economic Express (Nepali Music Industry), Capital Market Research and Development Pvt. Ltd, Kathmandu.

Nordgård, D. (2014) "Analysing Norway's Experience from Adopting On-Demand Streaming: Exceptions or Rules to A Future Economy?", Vienna Music Business Research Days 2014, Vienna, pp. 1-11.

Oestreicher-Singer, G. \& Zalmanson, L. (2013) "Content of community? A digital business strategy for content providers in the social age", MIS Quarterly, vol. 37 no. 2, pp. 591-616.

Ogden, J. R., Ogden, D. T. \& Long, K. (2011) "Music Marketing: A History and Landscape", Journal of Retailing and Consumer Service, vol. 18, no. 2, pp. 120-125.

Pathak, D. N. (2017) "Melodramatic South Asia: In Quest of Local cinemas in the Region", Journal of Human Values, vol. 23, no. 3, pp. 167-177.

Pettipas, C. \& Jago Da, K. (2012) "Creating an Independent Music Business in Canada: A Case Study", Journal of Enterprising Culture, vol. 20, no. 2, pp. 227-243.

Picard, R. G. (2004) "A Note on Economic Losses Due to Theft, Infringement, and Piracy of Protected Works", Journal of Media Economics, vol. 17, no. 3, pp. 207-217.

Sanchez-Franco, M. \& Rondan-Cataluña, F. J. (2010) "Connection between Customer Emotions and Relationship Quality in Online Music Services", Behaviour and Information Technology, vol. 29, no. 6, pp. 633-651.

Schumpeter, J. A. (2012) The Theory of Economic Development, Transaction Publishers, New Brunswick, U.S.A and London, UK.

Soundcharts (2019) "Music Market Focus: China Streaming and Recording Business". Available at https://soundcharts.com/blog/chinese-recording-market-streaming (January 30, 2020).

Spotts, H. E. (2010) "We'd Rather Fight than Switch: Music Industry in a Time of Change", Journal of the International Academy for Case Studies, vol. 6, no. 5, pp. 33-46.

Stirr, A. M. (2017) Singing Across Divides: Music and Intimate Politics in Nepal, Oxford University Press, New York.

Sturman J. (2019) The SAGE International Encyclopedia of Music and Culture, SAGE Publication, California.

Subedi, G. (2019) "From Physical to Digital". Available at http://ecs.com.np/features/from-physical-to-digital (August 10, 2019).

Thomes, T. P. (2013) "An Economic Analysis of Online Streaming Music Services", Information Economics and Policy, vol. 25, no. 2, pp. 81-91.

Tingey, C. (1990) "Heartbeat of Nepal: The Pancai Baja", Royal Nepal Academy, Kathmandu.

Waldfogel, J. (2012) "Copyright Research in the Digital Age: Moving from Piracy to the Supply of New Products", The American Economic Review, vol. 102, no. 3, pp. 337-342.

Waldfogel, J. (2012) "Digitization and Copyright: Some Recent Evidence from Music", Communications of the ACM, vol. 55, no. 5, pp. 35-37.

Whelpton, J. (2005) A History of Nepal, Cambridge University Press, Cambridge, UK.

Wikström, P. (2009) The Music Industry: Digital Media and Society Series, Polity Press, Cambridge, UK. 